\title{
Antipsychotic effects on cognition in schizophrenia: A meta-analysis of randomised controlled trials
}

\author{
Georgina Guilera* \\ Oscar Pino** \\ Juana Gómez-Benito* \\ J. Emilio Rojo** \\ * Facultat de Psicologia, Universitat de \\ Barcelona \\ ** Servei de Psiquiatria, Hospital de \\ Granollers - Benito Menni Centre \\ Assistencial en Salut Mental, Barcelona \\ SPAIN
}

\begin{abstract}
Background and Objectives: Several studies have shown an improved performance on neuropsychological tests among patients treated with atypical antipsychotics compared to traditional ones. Here we present a meta-analysis of various randomised control trials with the aim of exploring whether patients treated with atypical agents obtain better results than those treated with traditional ones.

Methods: The studies to be included were located electronically in November 2008 via the Medline database. A systematic review and a meta-analysis were undertaken; effect sizes were combined according to the random effects model. The effects of several moderating variables were evaluated.

Results: The results, based on 18 independent studies $(\mathrm{N}=1808)$, indicate that in terms of the global cognitive index atypical antipsychotics offer minor benefits compared to typical agents as regards the cognitive function of patients, the mean effect size being 0.17 (95\% CI $0.04-0.29)$. This observed effect was similar across the studies despite differences in their quality, the dose of haloperidol, the duration of treatment, pharmaceutical industry support, or the atypical antipsychotic used (all $p>0.05$ ).

Conclusions: The results suggest that compared to typical antipsychotics, atypical drugs produce a slight improvement in the global cognitive index, and several cognitive domains show a slight improvement in the neuropsychological performance of patients. We encourage further research on the relative effectiveness of several atypical antipsychotics.
\end{abstract}




\section{Introduction}

Schizophrenia is a mental disorder characterised by symptoms such as hallucinations, disorganised thought and language, cognitive impairments, loss of goal-directed behaviour, and impaired social functioning, and it usually has devastating effects on the individual and the individual's family environment ${ }^{1}$.

In recent years, research has highlighted the importance of cognitive functions in schizophrenia $^{2}$ and they have been related to the degree of functionality and prognosis presented by such patients ${ }^{3,4}$, their psychosocial adjustment ${ }^{5}$, their degree of adaptation to the workplace 6,7 , and their quality of life ${ }^{8}$.

Since the appearance of chlorpromazine in the 1950s, treatments for schizophrenia have focused on the positive symptoms of the disorder. Subsequent research led to the development of the first atypical antipsychotics, which blocked not only D2 receptors but also 5-HT2 ones, thus enabling the action of D2 antagonists to be reversed. This results in a reduction in the amount of dopamine in the mesolimbic and nigrostriatal pathways, which diminishes the extrapyramidal side effects of these drugs. Although atypical antipsychotics were initially developed with the aim of reducing such side effects their dual mechanism of action also meant that they increased dopaminergic and acetylcholine activity in the prefrontal cortex and hippocampus ${ }^{9,10}$, areas that are involved in various cognitive activities. Consequently, numerous researchers have hypothesised that atypical antipsychotics should have an enhancing effect on cognition, and the number of studies that include an evaluation of cognitive function has risen considerably ${ }^{11,12}$. In general terms these have shown an improved performance on neuropsychological tests among patients treated with atypical antipsychotics compared to traditional ones, and comparative studies have subsequently demonstrated improvements for olanzapine ${ }^{1}$, ziprasidone $^{13}$ and risperidone ${ }^{14}$. However, pharmaceutical companies principally sponsor those trials with a clear interest in specific outcomes, and thus the effect of new-generation antipsychotics on cognition remains a controversial issue about which no consensus has yet been reached.

In addition, a close examination of these studies from a methodological point of view reveals that many of them have important limitations, which means that only partial conclusions can be drawn. These limitations concern three broad areas: the study design, the pharmacological strategy used and how it was monitored, and the neuropsychological tests administered.

As regards the first of these, only a small number of double-blind studies have been published on cognitive enhancement in schizophrenia, which is problematic since non-blinded cognitive studies may be biased $^{15}$; as a result, the samples compared are often not completely heterogeneous.

With respect to the therapeutic strategy followed with the drugs used the controversy rests on the fact that dosing strategies often vary between studies, or no equivalent doses of the substances administered are presented. This makes it difficult to quantify not only the therapeutic doses that would be most beneficial in terms of cognition but also any opposing effects they might have. Research has regularly failed to control for the lingering influences of previous antipsychotic treatment, or for the effects of other concomitant medicines, such as antidepressants, used to control side effects, or treatments used to control agitation or induce sleep ${ }^{16}$. 
Finally, in terms of neurocognitive tests, many studies do not control for practice or learning effects during test administration, and nor are adequate tests to measure cognition always used. Indeed, one of the most controversial issues at present concerns the lack of consensus over which tests should be used to compare cognitive performance, with many research groups using different instruments in their studies. Some attempts have been made to reach a consensus in this regard, for example, the MATRICS (Measurement and Treatment Research to Improve Cognition in Schizophrenia) initiative ${ }^{17,18}$, which seeks to unify the assessment criteria in controlled neurocognitive trials and stimulate the develop- ment of new drugs that have an enhancing effect on cognition.

In the present study we sought to address this last issue by establishing various cognitive domains or areas relating to the different aspects of neurocognition. Initially, the classification system used was based on the review proposed by Nuechterlein and colleagues ${ }^{19}$ as part of the MATRICS programme; however, other aspects of cognition were added. Table I presents the domains that were finally taken into consideration, together with the corresponding neuropsychological tests. In addition, we established a consensus criterion whereby the tests used must be generally accepted as a measure of some aspect of neurocognition and appear in the Lezak manual ${ }^{20}$.

Table I

Cognitive domains and their corresponding neuropsychological tests

Cognitive domain

1 Attention/vigilance

2 Reasoning and problem solving

3 Verbal learning and memory

4 Visual learning and memory

5 Language and Verbal Comprehension

6 Working Memory

7 Speed of Processing

8 General intellectual functioning

9 Automaticity and procedural learnings

10 Psychomotricity

11 Perceptual processing
Tests

Continuous Performance Test, Stroop, Trail Making Test-B, TMT-A-B, CANTAB Rapid Visual Information Processing Test. Wisconsin Card Sorting Test, Block Design, Maze Test (WISC-R), Object Assembly (WAIS), Picture Completion (WAIS), Hooper Visual Organization Test, CANTAB Intra-Extra Dimensional, CANTAB Stockings of Cambridge.

Logical Memory (WMS-R), Verbal Pairs (WMS-R), Verbal List Learning Immediate and Delayed Recall, California Verbal Learning Test, Rey and Crawford Auditory Verbal Learning Test, Story Recall (Auditory Comprehension Test), Hopkins Verbal Learning, Paragraph Recall, Rivermead Behavioural Memory Test.

Figural Memory (WMS-R), Visual Memory (WMS-R), Visual Reproduction (WMS-R), Design Fluency Test, Rey-Taylor Complex Figure Copy Test, Self-Ordered Pointing Task.

Similarities (WAIS-R), Boston Naming Test.

Consonant Trigram Test, Visual Span (WMS-R), Verbal Span (WMS-R), Spatial Working Memory Test, Letter-Number Sequencing Test, Dot Test of Visuospatial Working Memory.

Controlled Oral Word Association Test, Category fluency, Letter Fluency, Action Fluency, Digit Symbol Substitution Test (WAIS-R), TMT-A, Reaction Time, Ruff Figural Fluency Test, Regard's Figural Fluency Task, CANTAB Reaction and Movement Time Test. QI (WAIS, WAIS-R), Peabody Picture Vocabulary Test, Minimental, New Adult Reading Test.

Tower of Toronto.

Finger Tapping Test, Grooved Pegboard Test. Benton Judgement of Lines. 
The abovementioned limitations mean that it has not been possible to conclude whether atypical antipsychotic agents really improve neuropsychological performance or whether traditional antipsychotics simply make it worse ${ }^{21}$. In such a diverse context, meta-analytic procedures are a good way of trying to overcome such shortcomings since they allow the results obtained in the different original studies to be aggregated, thus broadening the scope of any conclusions.

Here we present a meta-analysis of various randomised control trials in which the cognitive functions of several atypical antipsychotics (amisulpride, clozapine, olanzapine, quetiapine, risperidone and ziprasidone) were measured with the aim of exploring whether patients treated with atypical agents obtain better results than those treated with traditional ones.

In this regard, it is important to mention two recent studies. Firstly, a meta-analysis by Woodward et al. ${ }^{22}$ concluded that patients receiving atypical antipsychotics perform moderately better on neuropsychological tests than do those treated with traditional antipsychotics. Here we build on this study by adding new atypical antipsychotics (amisulpride and ziprasidone), and we also update the number of studies by including those published over the last four years. Another study, the CATIE trial conducted by Keefe et al. ${ }^{23}$, is a randomised controlled trial with a considerable sample size (1460 patients at baseline) that compares the effect of a traditional antipsychotic (perphenazine) with a number of atypical ones (olanzapine, quetiapine, risperidone and ziprasidone). This study is included in the present meta-analysis, but we also address the question at hand in a more general way by increasing the sample size and generalising the results to a larger number of traditional and atypical antipsychotics used in everyday clinical practice.

\section{Materials and methods}

\section{Criteria for the inclusion of studies}

In order to determine the neurocognitive effects of atypical antipsychotics (amisulpride, clozapine, olanzapine, quetiapine, risperidone and ziprasidone) in schizophrenic patients the aim was limited to those randomised controlled trials that compare one atypical antipsychotic with another traditional one in patients diagnosed with schizophrenia, or a schizoaffective or schizophreniform disorder, in accordance with DSM (American Psychiatric Association) or ICD (World Health Organisation) criteria.

The search was limited to randomised controlled trials which: a) examined adult patients, aged between 16 and 65, diagnosed with schizophrenia, or a schizoaffective or schizophreniform disorder; b) used at least one standardised neuropsychological test that appears in the Lezak manual ${ }^{20}$ and which therefore has been generally accepted as a measure of some aspect of neurocognition; and c) present the necessary data to estimate an effect size (i.e., means and standard deviations on neuropsychological measures, or $t$, $F$, or $p$ values). Studies published in journals written in English were included. Those studies that did not satisfy the inclusion criteria were excluded from the meta-analysis.

\section{Identification of documents}

Studies were located electronically in November 2008 via the Medline database, adopting the search strategy described below:

schizophren* and (cognit* or neuropsychol* or neurobehavioral manifestati*) and (olanzapin* or clozapin* or risperidon* or ziprasidon* or quetiapin* or amisulpri*) 
In addition, the references of each document, as well as those of other reviews, were checked in order to prevent the omission of any study 16,22,24-26.

\section{Data collection and coding}

Two reviewers independently examined the titles and summaries of documents in order to decide which studies, having satisfied the established criteria, could be included. Both reviewers extracted the data from all the documents, and in the event of any disagreement their decisions were documented and discrepancies resolved by consensus. In those cases where additional information on the studies was required, the authors of the studies were contacted directly.

Several variables were coded, namely: the antipsychotics used; the mean or modal dose of the typical antipsychotic, where applicable (where a range was provided, the mean value was used); the cognitive domain explored; the diagnosis of the sample; the duration of the study; the quality of the study; and any financial support from pharmaceutical companies.

The various follow-up measures were coded according to the following criteria: short-term treatment (up to 12 weeks), medium-term treatment (between 12 and 26 weeks), long-term treatment (more than 26 weeks), and last observation carried forward (LOCF).

Finally, the quality of the studies was evaluated by the Jadad scale ${ }^{27}$. A total possible rating from 0 to 5 points was assigned, based upon the following criteria ( 1 if yes, 0 if not): study described as randomised, adequateness of randomisation, study described as double blind, adequateness of blindness, and description of withdrawals and dropouts.

\section{Statistical analysis}

\section{Calculating effect sizes}

The effect size calculated was Hedges' unbiased $g^{28}$ using post-treatment group means and standard deviations, the statistics $t, F$ or the exact $p$ value. The effect size was calculated for each neuropsychological test. A weighted average effect size estimate was computed for each cognitive domain and the global cognitive index, the latter representing a weighted mean of the different cognitive domains.

In order not to violate the independence of the samples, the effect sizes of the studies that tested more than one atypical antipsychotic arm were combined to obtain a single overall measure in each study. For studies that included more than one-follow-up assessment, only data from the last retest were used in order to explore the effect of antipsychotics over a longer period of time. In those studies that presented data as logarithms or medians, which could indicate asymmetry of the data, it was decided to exclude the corresponding measures.

The criterion to interpret effect sizes was based on small $(\mathrm{g}=0.2)$, moderate $(\mathrm{g}=0.5)$ and large $(g=0.8)^{29}$.

\section{Combining effect sizes}

Effect sizes were combined according to the random effects model in order to apply the results to the universe of possible studies. Each effect size was weighted by the inverse of its variance ${ }^{30}$, and the mean effect size, the 95\% confidence interval and the corresponding $Z$ value and statistical significance were obtained. The homogeneity of the effect sizes was examined by calculating the $Q$ statistic ${ }^{30}$; the acceptance of a null hypothesis for homogeneity would indicate that the dispersion of effect sizes compared to the mean is not 
greater than what is expected due to sampling error, whereas rejection would indicate that the variance between the effect sizes is greater than expected for said error, and may therefore be influencing other variables, such as the characteristics of the study. The effects of moderating variables were evaluated by the weighted analysis of variance where these were categorical, while in the case of continuous variables metaregression was used ${ }^{30}$.

Effect sizes, and their combination, were calculated with the Comprehensive MetaAnalysis version 2 software ${ }^{31}$, with the significance level set at 0.05 .

\section{Outliers and publication bias}

The presence of outliers was explored through the graphic representation of a boxplot. Given that studies which produce significant results tend to be published with greater frequency than those that produce null results, we explored the possibility that the results of the present study were biased by what is referred to as the file-drawer problem. Consequently, the fail-safe $\mathrm{N}$ statistic $^{32}$ was calculated, which indicates the number of unpublished studies necessary to make the mean effect size non-significant. In addition, the effect sizes relative to the global cognitive index were correlated with the corresponding sample sizes.

\section{Results}

After reviewing the abstracts of the studies identified by the search and adopting the inclusion criteria described above, a total of 18 articles $(\mathrm{N}=1808)$ were collected, the characteristics of which are set out in Table II.

As can be seen, and given the presence of multiple arms in some articles, ten studies analyse risperidone, eight concern olanzapine, three use clozapine, a further three refer to quetiapine, and only one analyses ziprasidone. None of the randomised controlled trial used amisulpride as the comparison group. As regards the typical antipsychotic, most of the studies administer haloperidol, with the exception of some that use zuclopenthixol ${ }^{34}$, perphenazine $^{23}$, fluphenacine ${ }^{41}$, or a combination of several typical drugs ${ }^{37}$. Following the division proposed by Woodward and coworkers ${ }^{26}$, half of the studies use mean doses of haloperidol (or an equivalent) above 10 $\mathrm{mg}$ /day. The majority of articles employ a double-blind methodology (88.89\%), work with a sample of patients diagnosed with schizophrenia (72.22\%), last a maximum of twelve weeks $(50.00 \%)$, have an assigned quality score of $3(50.00 \%)$, and have received funding from the pharmaceutical industry (72.22\%). The mean sample size is 102 patients, while the value of the mode is 33 .

One outlier was detected ${ }^{38}$, although its removal did not produce a substantial variation in the global cognitive index. The analysis of publication bias indicated the need to add 38 studies in order to eliminate the statistical significance of the mean effect size relative to the global cognitive index. Table III presents the effects of atypical antipsychotic agents compared to traditional ones, for both each domain and the global cognitive index. Analysis of the homogeneity between studies for the global cognitive index revealed that the dispersion of effect sizes compared to the mean is not greater than that expected due to sampling error $\left(\mathrm{Q}_{\mathrm{B}(17)}=24.11, \mathrm{p}=0.12\right)$.

In terms of the global cognitive index the results of the meta-analysis indicate that atypical antipsychotic agents present minor benefits over typical ones as regards the cognitive function of patients, the mean effect size being 0.17 ( $p<0.01)$. More specifically, this 


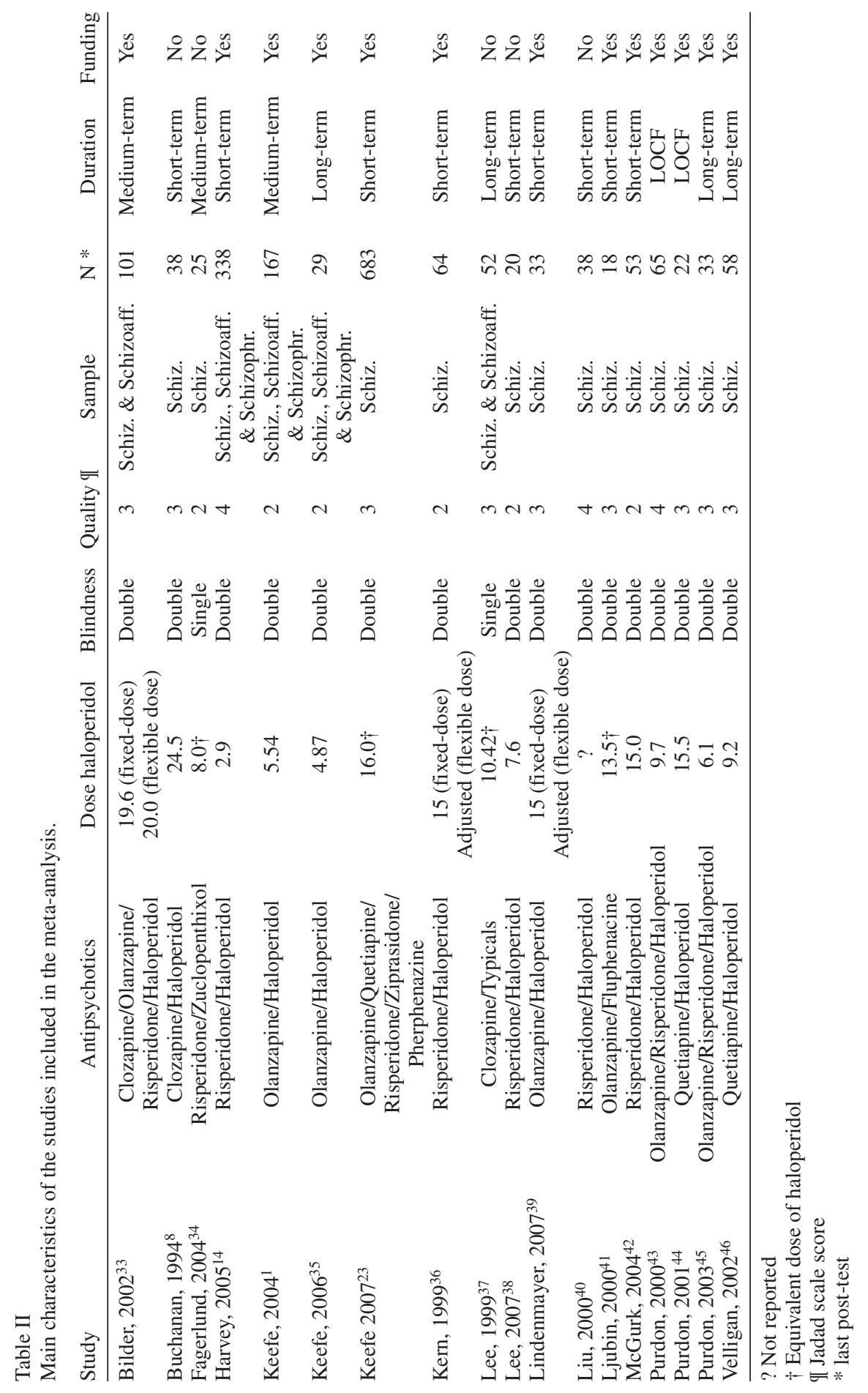


Table III

Atypical versus typical antipsychotics effects

\begin{tabular}{lccccccc} 
Cognitive domain & $\mathrm{k}$ & $\mathrm{N}$ & $\mathrm{g}$ & $95 \% \mathrm{CI}$ & $\mathrm{Z}$ & $\mathrm{p}$ \\
\hline Attention and vigilance & 12 & 1574 & 0.06 & $-0.04,0.15$ & 1.20 & 0.23 \\
Automaticity and procedural learning & 2 & 85 & 0.27 & $-0.13,0.67$ & 1.31 & 0.19 \\
General intellectual functioning & 3 & 184 & 0.16 & $-0.21,0.52$ & 0.84 & 0.40 \\
Language and verbal comprehension & 3 & 179 & 0.38 & $0.15,0.62$ & 3.22 & $<0.01$ \\
Perceptual processing & 2 & 136 & 0.04 & $-0.50,0.58$ & 0.14 & 0.89 \\
Psychomotricity & 5 & 387 & 0.29 & $0.11,0.47$ & 3.13 & $<0.01$ \\
Reasoning and problem solving & 12 & 1569 & 0.07 & $-0.07,0.21$ & 0.96 & 0.33 \\
Speed of processing & 11 & 909 & 0.26 & $0.13,0.39$ & 3.99 & $<0.01$ \\
Verbal learning and memory & 11 & 1615 & 0.19 & $-0.01,0.39$ & 1.84 & 0.07 \\
Visual learning and memory & 6 & 725 & 0.16 & $-0.05,0.38$ & 1.54 & 0.12 \\
Working memory & 8 & 1167 & 0.02 & $-0.10,0.15$ & 0.33 & 0.74 \\
\hline Global cognitive index & 18 & 1808 & 0.17 & $0.04,0.29$ & 2.61 & $<0.01$ \\
\hline
\end{tabular}

k: number of studies; N: sample size; $\mathrm{CI}$ : confidence interval.

improvement is present in the cognitive domains of automaticity and procedural learning ( $\mathrm{g}=0.27)$, language and verbal comprehension $(\mathrm{g}=0.38)$, psychomotricity $(\mathrm{g}=0.29)$, speed of processing $(g=0.26)$, verbal learning and memory ( $\mathrm{g}=0.19)$, and visual learning and memory ( $\mathrm{g}=0.16$ ); however, it only reaches significance in the case of language, speed of processing and psychomotricity.

The observed effects on global cognitive performance were similar across the 18 studies included in the analysis, despite differences in their quality $\left(\mathrm{Q}_{\mathrm{R}(1)}=0.02, \mathrm{p}=0.89\right)$, dose of haloperidol $\left(\mathrm{Q}_{\mathrm{R}(1)}=0.06, \mathrm{p}=0.80\right.$; $\mathrm{Q}_{\mathrm{B}(1)}=0.03, \mathrm{p}=0.85$, according to the cut-off points used in the study by Woodward $e t$ $\left.a l .{ }^{26}\right)$, duration of treatment $\left(\mathrm{Q}_{\mathrm{B}(3)}=1.24, \mathrm{p}=\right.$ $0.74)$, pharmaceutical industry support $\left(\mathrm{Q}_{\mathrm{B}(1)}\right.$ $=0.45, \mathrm{p}=0.50)$, or atypical antipsychotic used $\left(\mathrm{Q}_{\mathrm{B}(4)}=5.29, \mathrm{p}=0.26\right)$. Given the lack of variability in the data, neither the effect of blindness nor the patients' diagnosis was analysed. The correlation between the effect sizes of the global cognitive index with the sample size of the studies was -0.36 , indicating that studies with a larger sample size tend to report lower effect sizes, and vice-versa.

\section{Discussion}

\section{Main findings}

The results of the comparison between traditional and atypical antipsychotics reveal that the latter are associated with better global cognitive performance, although this improvement is a slight one. The obtained effects are somewhat lower than those found by Woodward and et al. ${ }^{22}$. If we focus more specifically on cognitive domains it can be seen that atypical antipsychotics are associated with a slight but significant improvement (between 0.16 and 0.38 ) in automaticity and procedural learning, general intellectual functioning, language and verbal comprehension, psychomotricity, speed of processing, verbal learning and memory, and visual learning and memory. Although this improvement remains slight it is important to highlight that such increases occur in areas that are traditionally affected by schizophrenia, such as processing speed and learning, which are more related to the functionality and psychosocial adaptation of patients. 
The improvement in psychomotricity and speed of processing could be explained by the reduced number of extrapyramidal effects that atypical antipsychotics produce compared to traditional ones, this leading to better and faster execution on psychomotricity tests. As regards the improvement in verbal, visual and procedural learning this could be explained via two different hypotheses. The first would be that the low affinity of atypical antipsychotics for D2 dopamine receptors and the increase in serotoninergic effects produced by these drugs lead to increased amounts of dopamine and acetylcholine in the prefrontal dorsolateral cortex and the hippocampus ${ }^{9,10}$, areas that are traditionally associated with the acquisition and consolidation of new knowledge; as a result the performance of these areas would be slightly improved. The second hypothesis has to do with practice and learning effects. Some authors have reported that patients receiving atypical antipsychotics show more practice effects on neuropsychological tests than do those treated with traditional drugs ${ }^{47}$, and therefore this type of effect would be more clearly observed on tests of learning.

\section{Clinical implications}

One aspect that needs to be underlined is that differences in the execution of neuropsychological tests do not always represent a change in cognitive function, since the former may be due to other aspects such as motivation, negative symptomatology, different effects of learning or simply practice effects. Although it would appear that the latter effects have already been controlled for in other studies, we cannot rule out the possibility that other intermediate variables may modulate neuropsychological performance, nor provide evidence of the extent to which they do so.
It is also important to consider the practical significance of the slight cognitive change or improvement found in the present study, in other words: what do these quantitative changes represent in the real life of the patient? To illustrate the magnitude of this effect let us consider what an improvement with an effect size of 0.26 would represent in terms of speed of processing for a young adult aged 20-24 according to the Spanish norms for the Digit Symbol subtest of the WAIS-III ${ }^{48}$. To achieve such an effect size the subject would only have to fill in four more squares during the two minutes that the test lasts. If we analyse the cognitive domain of verbal learning in a patient of the same age and according to the delayed word list of the WMS-III ${ }^{49}$, we find that the subject could produce an effect size of 0.16 merely by remembering one more word on the delayed recall test. This suggests that any clinical implications of the results obtained should be proposed with caution.

Another controversial clinical factor has to do with how long treatment should be administered before a mild improvement is obtained. Here we found no significant differences according to duration of treatment, which suggests that any slight improvement is produced as soon as second-generation antipsychotics are given. Nevertheless, future studies should explore whether this effect is produced concomitantly with the administration of atypical antipsychotics or if there is a temporal effect linked to the change in therapeutic strategy.

In recent years some studies have reported differences in cognitive performance according to the dose of antipsychotics given, a beneficial effect on cognition being obtained with traditional antipsychotics when these are compared at low doses ${ }^{50}$. In the present study, as in the report by Woodward et $a l .{ }^{26}$, we analysed this aspect by compar- 
ing studies that administered a dose of haloperidol lower than $10 \mathrm{mg}$ with those where this dose was higher than $10 \mathrm{mg}$, but found no significant differences in terms of these variables. At all events we are aware that this cut-off point falls within the medium-high range for pharmacological treatment and is not strictly a low dose. We were unable to use a considerably lower cut-off dose due to a lack of variability in the data, and thus our results do not enable strong conclusions to be drawn as to the cognitive effect that might be produced at low doses.

\section{Limitations of the study}

One of the main limitations of the present study concerns the small number of studies referring to some of the cognitive domains, and therefore extreme prudence should be exercised when drawing conclusions from the present results. Another weakness is related to the almost complete absence of studies with certain characteristics, which meant that several analyses could not be carried out while others must be considered tentative. Although in cases where it proved necessary we decided to contact the corresponding authors, it was not always possible to obtain the required information. Furthermore, the fact that we did not encounter effects in the moderating variables could be due to the limited number of studies and, as a consequence, the low power of the $Q$ statistic for detecting such effects. Once again, therefore, the results described in the present study should be interpreted with caution. Another issue that should be borne in mind is that most of the studies included as randomised controlled trials concerned subjects aged 16-65, which could lead to some confusion with cognitive deterioration emerging during the sixth decade of life; moreover, psychiatric patients are known to be more likely to suffer from cognitive deterioration in older age. Our initial idea was to limit our sampling to studies of patients up to the age of 55, but most of the articles did not allow us to conduct our analyses without including this last decade. As a result we decided to include all the studies, even though this runs the risk of a certain bias. Future research in this area should avoid the inclusion of patients over the age of 55 .

In close relation to the previous point, another limitation refers to the use of very restrictive inclusion criteria (i.e., only randomised controlled trials, patients aged between 16 and 65, and only standardised scale), which prevented many studies that explore the effects of antipsychotics from being included since they did not satisfy these criteria.

Selecting the final post-test values as an objective measure may also have affected the results obtained; however, we chose this option because we wanted the pharmacological treatment to be beneficial to patients in the long-term.

As in any meta-analysis it is important to consider the possibility of publication bias. The present study only includes studies published in scientific journals, although it should be borne in mind that many drug trials are promoted by the pharmaceutical industry and, as a consequence, it is possible that studies which do not produce positive results are never published. We analysed this potential bias by computing the fail-safe $\mathrm{N}$ statistic, which indicated that 38 studies would need to be added to counteract the slight positive effect on cognition achieved by atypical antipsychotics. Although most of the studies analysed $(72.22 \%)$ were backed by the pharmaceutical industry it is difficult to imagine that as many as 38 other studies have found no effect on cognition and have 
gone unpublished. However, it should be noted that there is a moderate correlation between the values of the effect sizes and the corresponding sample sizes.

\section{Conclusions and future research}

As regards the effects of antipsychotic medication on cognitive function in patients with schizophrenia the results of the metaanalyses allow us to conclude that atypical antipsychotics present slight benefits compared to traditional agents. However, the present study has several limitations and future research should take these into consideration and extend the analysis in order to address the gaps that remain in this area. Another controversial aspect has to do with the therapeutic doses required before antipsychotics achieve a positive effect on cognition, as at present this dose is inferred from the need to treat positive symptoms, this being the purpose for which these drugs were designed. Future lines of research and associated initiatives should therefore study the design of new drugs whose primary aim is to improve cognition, and seek to determine the therapeutic dose required to achieve this. Finally, it has been seen that compared to typical agents, atypical antipsychotics produce a slight improvement in the global cognitive index, and several cognitive domains show a slight improvement in terms of the neuropsychological performance of patients. These results do not provide unequivocal evidence that atypical antipsychotics act as cognitive enhancers, since practice effects or simply a mild cognitive deterioration brought on by the use of traditional antipsychotics could be behind these observations. Therefore, further studies are required to determine whether second-generation antipsychotics do indeed enhance cognitive function. At all events, given that the neuropsychological performance of patients diagnosed with schizophrenia is normally between one and two standard deviations below the control group, there is indeed a need to clarify whether antipsychotics can normalise the cognitive functioning of these patients. In this regard, one of the key aspects to bear in mind is the impact of any improvement on the psychosocial functioning of patients (both in clinical trials and in primary healthcare).

All of these efforts must be linked to improving clinical practice and psychopharmacological treatment since, together with a correct neuropsychological assessment, they can provide us with additional information of a prognostic nature and guide us towards the selection of other, complementary therapies such as rehabilitation or re-entering the workplace.

\section{Acknowledgements}

We would like to thank those authors who supplied additional information when requested.

\section{Funding}

This work was supported by the "Departament d'Universitats, Recerca i Societat de la Informació de la Generalitat de Catalunya" (2007FIC 00736 y 2005SGR 00365) and by the "Ministerio de Ciencia y Tecnología de España" (SEJ2005-09144-C02-02) under the European Regional Development Fund (ERDF). 


\section{References}

1. Keefe RSE, Seidman LJ, Christensen BK, Hamer RM, Sharma T, Sitskoorn MM, et al. Comparative effect of atypical and conventional antipsychotic drugs on neurocognition in first-episode psychosis: A randomised, double-blind trial of olanzapine versus low doses of haloperidol. Am J Psychiatry 2004; 161: 985-995.

2. Harvey PD, Sharma T. Understanding and treating cognition in schizophrenia: A clinician's handbook. London, UK: Martin Dunitz; 2002.

3. Green MF, Kern RS, Heaton PK. Longitudinal studies of cognition and functional outcome in schizophrenia: Implications for MATRICS. Schizophr Res 2004; 72: 41-51.

4. Green MF, Olivier B, Crawley JN, Penn DL, Silverstein S. Social cognition in schizophrenia: Recommendations from the measurement and treatment research to improve cognition in schizophrenia new approaches conference. Schizoph Bull 2005; 31: 882-887.

5. Green MF. What are the functional consequences of neurocognitive deficits in schizophrenia? Am J Psychiatry 1996; 153: 321-330

6. McGurk SR, Meltzer HY. The role of cognition in vocational functioning in schizophrenia. Schizophr Res 2000; 45: 175-184.

7. Sergi MJ, Kern RS, Mintz J, Green MF. Learning potential and the prediction of work skill acquisition in schizophrenia. Schizophr Bull 2005; 31: 67-72.

8. Buchanan RW, Holstein C, Breier A. The comparative efficacy and long-term effect of clozapine treatment on neuropsychological test performance. Biol Psychiatry 1994; 36: 717-725.

9. Ichikawa J, Ishii H, Bonaccorso S, Fowler WL, O'Laughlin IA, Meltzer HY. 5-HT(2A) and D(2) receptor blockade increases cortical DA release via 5-HT(1A) receptor activation: A possible mechanism of atypical antipsychotic-induced cortical dopamine release. J Neurochem 2001; 76: 1521-1531.

10. Ichikawa J, Li Z, Dai J, Meltzer HY. Atypical antipsychotic drugs, quetiapine, iloperidone, and melperone, preferentially increase dopamine and acetylcholine release in rat medial prefrontal cortex: Role of 5-HT1A receptor agonism. Brain Res 2002; 956: 349-357.

11. Vilaplana Traveria E, Noguer Carmona S, Gallo de Puelles P. Estudi bibliomètric sobre esquizofrènia a Espanya (1999-2003): anàlisi de col-laboracions entre autors $1^{\text {st }}$ edition. Barcelona: Fundació SENY; 2004.

12. Noguer-Carmona S, Gallo P, Parada A, GarcíaDuran Huet M, Méndez-Vásquez RI, Suñén-Pinyol E. Es- tudio bibliométrico sobre esquizofrenia en España (19992004): productividad, impacto y colaboración, $2^{\text {nd }}$ edition. Barcelona: Fundació SENY; 2006.

13. Harvey PD, Siu CO, Romano S. Randomized, controlled, double-blind, multicenter comparison of the cognitive effects of ziprasidone versus olanzapine in acutely ill inpatients with schizophrenia or schizoaffective disorder. Psychopharmacology 2004; 172: 324-332.

14. Harvey PD, Rabinowitz J, Eerdekens M, Davidson M. Treatment of cognitive impairment in early psychosis: A comparison of risperidone and haloperidol in a large long-term trial. Am J Psychiatry 2005; 162: 1888-1895.

15. Harvey PD, Keefe RSE. Interpreting studies of cognitive change in schizophrenia with novel antipsychotic treatment. Am J Psychiatry 2001; 158: 176-184.

16. Keefe RSE, Silva SM, Perkins S, Lieberman JA. The effects of atypical antipsychotic drugs on neurocognitive impairment in schizophrenia: A review and metaanalysis. Schizophr Bull 1999; 25: 201-222.

17. Green MF, Nuechterlein KH. The MATRICS initiative: Developing a consensus cognitive battery for clinical trials. Schizophr Res 2004; 72: 1-3.

18. Kern RS, Green MF, Nuechterlein KH, Deng BH. NIMH-MATRICS survey on assessment of neurocognition in schizophrenia. Schizophr Res 2004; 72: 11-19.

19. Nuechterlein KH, Barch DM, Gold JM, Goldberg TE, Green MF, Heaton RK. Identification of separable cognitive factors in schizophrenia. Schizophr Res 2004; 72: 29-39.

20. Lezak M. Neuropsychological assessment, $4^{\text {rd }}$ edition. New York: Oxford University Press; 2004.

21. Carpenter WT, Gold JM. Another view of therapy for cognition in schizophrenia. Biol Psychiatry 2002; 51: 969-971.

22. Woodward ND, Purdon SE, Meltzer HY, Zald DH. A meta-analysis of neuropsychological change to clozapine, olanzapine, quetiapine, and risperidone in schizophrenia. Int J Neuropsychopharmacol 2005; 8: 457-472.

23. Keefe RSE, Bilder RM, Davis SM, Harvey PD, Palmer BW, Gold JM, et al. Neurocognitive effects of antipsychotic medications in patients with chronic schizophrenia in the CATIE trial. Arch Gen Psychiatry 2007; 64: 633-647.

24. Davis JM, Chen N, Glick ID. A meta-analysis of the efficacy of second-generation antipsychotics. Arch Gen Psychiatry 2003; 60: 553-564.

25. Serretti A, De Ronchi D, Lorenzi C, Berardi D. New antipsychotics and schizophrenia: A review on efficacy and side effects. Cur Medicinal Chemistry 2004; 11: 343-358.

26. Woodward ND, Purdon SE, Meltzer HY, Zald DH. A meta-analysis of cognitive change with haloperidol in clinical 
trials of atypical antipsychotics: Dose effects and comparison to practice effects. Schizophr Res 2007; 89: 211-224.

27. Jadad AR, Moore RA, Carroll D, Jenkinson C, Reynolds DJ, Gavaghan DJ, et al. Assessing the quality of reports of randomised clinical trials: Is blinding necessary? Control Clin Trials 1996; 17: 1-12.

28. Hedges LV. Distribution theory for Glass' estimator of effect size and related estimators. J Educational Statistics 1981; 6: 197-228.

29. Cohen J. Power analysis for the behavioral sciences. Hillsdale: Lawrence Erlbaum Associates; 1988.

30. Hedges LV, Olkin I. Statistical methods for metaanalysis. New York: Academic Press; 1985.

31. Borenstein M, Rothstein H. Comprehensive MetaAnalysis: A computer program for research synthesis. Englewood, NJ: Biostat; 1999.

32. Rosenthal R. The "file drawer problem" and tolerance for null results. Psychol Bull 1979; 86: 638-641.

33. Bilder RM, Goldman RS, Volavka J, Czobor P, Hoptman M, Sheitman B, et al. Neurocognitive effects of clozapine, olanzapine, risperidone, and haloperidol in patients with chronic schizophrenia or schizoaffective disorder. Am J Psychiatry 2002; 159: 1018-1028.

34. Fagerlund B, Mackeprang T, Gade A, Glenth $\Delta \mathrm{j} B Y$. Effects of low-dose risperidone and low-dose zuclopenthixol on cognitive functions in first-episode drugnaive schizophrenic patients. CNS Spectr 2004; 9: 364-374.

35. Keefe RSE, Seidman LJ, Christensen BK, Hamer RM, Sharma T, Sitskoorn MM, et al. Long-term neurocognitive effects of olanzapine or low-dose haloperidol in first-episode psychosis. Biol Psychiatry 2006; 59: 97-105.

36. Kern RS, Green MF, Marshall BD Jr, Wirshing WC, Wirshing D, McGurk SR, et al. Risperidone versus haloperidol on secondary memory: Can newer medications aid ?. Schizophr Bull 1999; 25: 223-232.

37. Lee MA, Javathilake K, Meltzer HY. A comparison of the effect of clozapine with typical neuroleptics on cognitive function in neuroleptic-responsive schizophrenia. Schizophr Res 1999; 37: 1-11.

38. Lee SM, Chou YH, Li MH, Wan FJ, Yen MH. Effects of antipsychotics on cognitive performance in drugnaive schizophrenic patients. Prog Neuro-Psychopharmacol Biol Psychiatry 2007; 31: 1101-1107.

39. Lindenmayer JP, Khan A, Iskander A, Abad MT, Parker B. A randomized controlled trial of olanzapine varsus haloperidol in the treatment of primary negative symptoms and neurocognitive deficits in schizophrenia. J Clin Psychiatry 2007; 68: 368-379.

40. Liu SK, Chen WJ, Chang CJ, Lin HN. Effects of atypical neuroleptics on sustained attention deficits in schizophrenia: A trial of risperidone versus haloperidol. Neuropsychopharmacology 2000; 22: 311-319.

41. Ljubin T, Zakic Milas D, Mimica N, Folnegovic-Smalc V, Makaric G. A preliminary study of the comparative effects of olanzapine and fluphenazine on cognition in schizophrenic patients. Hum Psychopharmacol 2000; 15: 513-519.

42. McGurk SR, Green MF, Wirshing WC, Wirshing DA, Marder SR, Mintz J, Kern R. Antipsychotic and anticholinergic effects on two types of spatial memory in schizophrenia. Schizophr Res 2004; 68: 225-233.

43. Purdon SE, Jones BD, Stip E, Labelle A, Addington D, David SR et al. Neuropsychological change in early phase schizophrenia during 12 months of treatment with olanzapine, risperidone, or haloperidol. Arch Gen Psychiatry 2000; 57: 249-258.

44. Purdon SE, Malla A, Labelle A, Lit W. Neuropsychological change in patients with schizophrenia after treatment with quetiapine or haloperidol. J Psychiatry Neurosci 2001; 26: 137-149.

45. Purdon SE, Woodward N, Lindborg SR, Stip E. Procedural learning in schizophrenia after 6 months of doubleblind treatment with olanzapine, risperidone, and haloperidol. Psychopharmacology 2003; 169: 390-397.

46. Velligan DI, Newcomer J, Pultz J, Csernansky J, Hoff AL, Mahurin R, et al. Does cognitive function improve with quetiapine in comparison to haloperidol?. Schizophr Res 2002; 53: 239-248.

47. Kasper S, Resinger E. Cognitive effects and antipsychotic treatment. Psychoneuroendocrinology 2003; 28: 27-38.

48. Wechsler D. Manual for the Wechsler Adult Intelligence Scale, $3^{\text {rd }}$ ed. San Antonio, Texas: Psychological Corporation; 1997.

49. Wechsler D. WMS-III: Wechsler Memory Scale, $3^{\text {rd }}$ ed. San Antonio, Texas: Psychological Corporation; 1997.

50. Mishara AL, Goldberg TE. A meta-analysis and critical review of the effects of conventional neuroleptic treatment on cognition in schizophrenia: opening a closed book. Biol Psychiatry 2004; 55: 1013-1022.

Address for correspondence:

J. Emilio Rojo

Servei de Psiquiatria

Hospital de Granollers

Benito Menni Centre Assistencial en Salut Mental,

Avinguda Francesc Ribas, s/n

08400 Granollers, Barcelona

SPAIN

Tel.: +34-938425035

Fax: +34-938404994

E-mail: 16735jrr@comb.es 